\title{
RESEARCH OBJECTIVES IN SOUTH AFRICAN NATIONAL PARKS
}

\author{
U DE V PIENAAR
}

\author{
Director of Nature Conservation \\ National Parks Boards of Trustees \\ Private Bag X404 \\ Skukuza \\ 1350
}

The primary purpose of any national park service in administering natural areas is to maintain an area's ecosystems in as nearly pristine a condition as possible. This means that ecological processes, including plant succession and the natural regulation of animal numbers, should be permitted to proceed as far as possible as they did under pristine conditions, and that modern man must be restricted to generally non-consumptive uses of these areas (Houston 1971).

If this ideal setting for administering the national conservation areas under our care was at all possible it would certainly simplify management of such areas considerably. Unfortunately, it is a hard and irrefutable fact that there is probably no part of the earth's surface today that is wholly unaffected by man and one could even say that there may be no truly natural environment left. National parks and nature reserves are in fact ecological islands which can rarely be self-regulatory, except perhaps in the case of certain remote desert, marine, polar and evergreen forest ecosystems. The influence of man within such conservation areas (as well as those adjoining such areas) is progressively increasing and they are consequently increasingly subject to human interference. It is now rarely possible for an area to be maintained as a natural unit merely by protection from outside influences.

Few, if any, of our South African national parks and nature reserves are completely self-contained ecological units and their problems are numerous and varied.

It is obvious therefore that the maintenance of most natural park ecosytems requires management in some form or other in order to prevent or compensate for man's altering of natural ecological relations. The commonly accepted approach to the management of national parks and the problems of its supporting research, declares that the objectives of management must be clearly stated.

The other option is to have no objectives of management in such precise scientific terms as prescribed patterns of vegetation with associated water bodies, soils, fauna and land use. In this case manage- 
ment relates only to the direct cause and effect of man's actions, planned or unplanned. Too many people destroy and disturb. Too few people and a lack of human predation allow vegetation and animal populations to develop in a self-destructive way within the confines of the park or reserve. This is a pragmatic strategy which concentrates on the numbers and behaviour of people with an eye on detailed ecological effect, without becoming bogged down in the fundamentals of the total ecosystem. This approach lacks appeal for scientists because of its inherent untidiness and holds dangers of long term impoverishing of the ecosystem. It is often, however, the only option open in the absence of a scientific institute to study the ecosystem as a whole (Boyd 1972).

The National Parks Board of South Africa has committed itself to managing the various natural ecosystems entrusted to its care in such a manner that they are kept as far as possible unimpaired for the enjoyment of future generations, and that the ecological conditions which led to their identification and proclamation as national parks are not substantially changed or impoverished. It is recognised, however, that national parks and nature reserves, no matter how large they are, are not stable entities - they are dynamic biological systems which change with time. Some changes are acceptable, but others are not. Diversity both of habitat and of species increases biological productivity and this can only be maintained through management policies which take cognisance of all the components (biotic and abiotic) of the ecosystems and which are aimed at maintaining relative stability in the ecosystems by a minimum of human interference. The scientific aim of wildlife management in our national parks is to diversify, whereas that of agriculture and forestry is to simplify (Boyd 1972).

Biological conservation and integrated management have no hope of success unless they are based on firm and factual biological data, obtained through research. It stands to reason that the primary objectives of any research program in our national parks should therefore be a study of ecosystems and their interrelationships, with the objective of supplying the managerial basis for maintaining optimum conditions within the ecosystems, without endangering the interdependency of the components or the quality of the environment. The primary consideration in management should be attainment of the proclaimed objectives with minimum human interference.

It has been found in practice that contingency measures may be necessary in all management schemes until research findings clarify particular problems. This necessity emphasises the importance of proper historical documentation, when planning has to be based on what can be determined from piecing together historical records, subject to objective evaluation of causes and consequences. A pragmatic attitude in research must be adopted and maintained in which human behaviour is a central theme and the integrated plan for scientific investigation of national parks must establish standards by which change is measured in human 
occupancy and behaviour, as well as that of the water, soils, vegetation and the main fauna.

In the mission-orientated research programs for our various national parks, a number of aspects are considered of primary importance for gaining a proper understanding of the complex ecosystems and their interrelationships.

\section{Boundaries and boundary influences}

Ideally, national parks and nature reserves should have natural boundaries such as major rivers, mountain ranges and watersheds. This unfortunately is seldom possible and all of our present national parks have man-imposed boundaries which have varying effects on the protected ecosystems. The effect of fences inevitably influences the viability of conserved areas and it is imperative to know where, how and when to fence. The erection of fences is a costly undertaking and a thorough study is necessary of all factors which may be influenced e.g. traditional migration routes of certain wildlife species, the availability of natural water as a controlling factor of animal movements and the associated dissemination of animal-borne diseases. In addition, studies have to be conducted to ascertain the best system of boundary control to counteract illegal activities such as poaching, arson and pollution.

In recent years functional game-deterrent fences have become commercially available. However, they are not very effective in controlling large and heavy pachyderms, for which specially constructed barriers had to be designed and erected e.g. around the perimeter of the Addo Elephant National Park and along the eastern and northern borders of the Kruger National Park.

\section{Basic resource information}

The foundation of any research program aimed at management should be a series of basic surveys to provide the knowledge of what we are trying to conserve. An assessment of the entire spectrum of abiotic components (i.e. geological formations, soils and water supplies) and biotic components (plant and animal species) is required. This is also necessary to establish the missing components in the existing chain of national parks and to properly motivate the proclamation of new national parks or reserves for their protection. Natural beauty is intertwined with scientific interest. The heritage of one automatically is the heritage of the other. Limits must be set as to what can and cannot be set aside for posterity. Only a small portion of the world today can be spared. This means that only the best areas must be chosen. These areas must be large enough to fulfil their purpose, and there must be a reasonable prospect of managing the chosen land with a combined management/research strategy (Boyd 1972). The identification and 
promotion of sites suitable for proclamation as new national parks obviously is one of the more important tasks of the National Parks Board's research unit.

On account of the diversity which is encountered in different national parks a separate research program has to be compiled for each area, and on the basis of the results forthcoming from the various investigations operational management plans are prepared. These management plans are incorporated in a master plan for the resource protection, interpretation and development of each park. Nothing is more useful for planning than accurate and complete resource information (preferably in the form of overlay maps), gathered through research programs. This should illustrate or delineate geological formations, soil and vegetation types, elevations, local climatic differences, location of major wildlife habitats, herd migration routes and other recent or historical wildlife information (Linn 1976). Data on the former distribution and abundance of species in the particular ecosystem is important when deciding on the reintroduction of locally or regionally extinct animal or plant taxa.

When the basic resource information has been obtained, it must somehow be organized to be meaningful. There are many ways to organize and store such information e.g. by making use of computerized programs, but zoning is one of the most widely used methods. The zones establish areas of the park within which certain activities may or may not be permitted, the kinds and size of developed sites that may or may not be established, and so forth, based upon the uniqueness, fragility and value of the various resources found within the zone (Linn 1976). The kinds and names of the zones will depend upon the specific needs and objectives of the particular park or park system in which the zoning is being done, but wherever possible provision should be made for one or more wilderness areas or primitive reference zones, where human interference or management practices of a manipulatory nature are strictly limited. Other zones may include such areas as intensive development zones, limited development zones or special and/or unique value zones. The systematic zoning of all our existing national parks is at present a priority project of the Board's research unit.

\section{Botanical research and management of the vegetation}

National parks are complex and dynamic entities and in selecting and administering them, we must be able to draw upon an immense range of knowledge from a wide array of scientific disciplines. One must know in scientific terms (as well as in aesthetic, economic or political terms), why a national park has been established. Consequently, it is essential to state and define the desired environmental conditions in the basic terms of water, soils, vegetation, animal and human communities. Vegetation is the best indication of status and trend in the environment and has been adopted internationally as a common basis for this purpose. 
Evaluation and restoration of natural factors that shaped the vegetation (the producer level of ecosystems) are the primary objectives of botanical research and vegetation management in our protected ecosystems. Where necessary, management procedures have been evolved which facilitate the manipulation of the floristic component of ecosystems to comply with the major objectives for which they are protected. Natural fires, for instance, have been instrumental in the shaping of the vegetation of many areas, and their influence is being restored or simulated in the form of prescribed or controlled burns.

It is also necessary to monitor and interpret successional and other changes taking place in the vegetation of a protected area. To achieve these declared aims in our botanical research and to serve as a basis for future studies, specific attention is given to the building up of complete herbaria, species lists and keys for the identification of all plant species in the protected ecosystem.

It is important to classify vegetation in terms of its floristic composition and structure in order to identify individual plant communities. The study of plant communities is then further pursued in terms of the function of the vegetation and the effects of various forms of treatment along predetermined gradients of variation within the different community types. Although broad plant communities have already been identified and described in our national parks, more detailed research is required and should incorporate aspects such as complete species composition, differentiating characteristics (both in terms of habitat and floristically), the relationship of plant communities to other community types and structural variation (expressed in terms of growth forms and their relative abundance).

Species composition of plants may be correlated with climate and substrate and is less variable than the structural features of the community which are easily influenced by factors such as fire or intensive grazing.

Plant community studies enable the determination of the geographical distribution of species from which an ecological (habitat) and phytosociological (community) indicator value may be attached to particular species.

Fire and grazing pressure are the two most controllable factors exerting an influence on vegetation. Both these factors as well as other variables which may contribute to vegetation changes (e.g. climate) receive considerable attention in our research plans and their effects on vegetation types and structure are determined so that, where necessary, they may be applied with anticipated results.

Animal-plant relationships and aspects such as habitat and quantitative and qualitative food preferences, carrying capacity and biomass form a common basis in all our ecological investigations.

Monitoring of vegetation trends, by means of fixed transect lines and/or check-point photography, is undertaken to ascertain long term 
successional changes or effects of various manipulative treatments of the vegetation and this is measured against vegetation composition and structure in exclosures, where man-made and other effects such as grazing and fire are excluded.

In similar vein, the early identification of factors leading to regression of habitats (such as bush encroachment, encroachment of unpalatable grasses or shrubs, erosion and eutrophication) and the devising of remedial measures to arrest or reverse such undesirable trends constitute an important aspect of research in all our parks. Habitat regression can be sparked off by many circumstances or by a combination of factors such as overutilisation of the vegetations, a harmful fire regime, soil erosion, droughts and floods.

A continuous monitoring system to warn against pollution of both aquatic and terrestrial habitats is also desirable. Here it is necessary to measure the incidence and to determine the detrimental effects of effluents and industrial wastes in rivers, fertilizers leaching from the soil and the indiscriminate use of insecticides, fungicides, arboricides and rodenticides. These factors usually arise in areas which are adjacent to conservation areas, and which influence the latter directly or indirectly.

In the same manner, it is the perpetual task of the conservation staff to identify and eradicate all exotic and invading plant (and animal) species from the natural areas where they have taken root. Some of the eradication campaigns can be protracted and very costly (as with the eradication of jointed cactus (Opuntia aurantiaca) in the Mountain Zebra National Park), and experiments are currently under way whereby biological agents are used for the control of undesirable exotics such as Hakea gibbosa in the Tsitsikama Forest and Coastal National Parks.

Closely linked with the vegetation in a habitat is the concept of shelter. Lack of adequate shelter in quality or quantity may mean poor population success, particularly in cold montane ecosystems such as the Golden Gate Highlands National Park.

\section{Animal community research}

To understand and interpret animal community dynamics it is imperative to have a thorough knowledge of the individual species in the community. The major objectives of our animal research efforts are therefore to undertake detailed studies of individual species, thus gaining a broad perspective of the bio-ecology of the species, with emphasis on those aspects which are of particular importance with regard to their conservation and management.

In view of the tremendous species diversity in the larger mammal component of South African national parks, research priorities are determined on the basis of species requiring particular management considerations. These species may be divided into two main categories i.e. those exerting most influence on their respective habitats and/or 
associated species such as elephant, hippo, buffalo, wildebeest, zebra, impala and springbok, on the one hand, and those which are most vulnerable to habitat changes and/or dominance by numerically stronger or more adaptable species, such as roan antelope, sable, tsessebe, Cape mountain zebra, bontebok, black wildebeest, red hartebeest, black rhino, cheetah, brown hyaena etc. on the other hand.

By studying individual species in detail it is hoped to accumulate sufficient knowledge of all the species in the community eventually to predict and interpret changes and to clearly differentiate between cause and effect phenomena.

Aspects receiving particular attention in these special bio-ecological animal studies include the following:

(a) Aspects relating to population dynamics including inter alia:

(i) information on reproduction, with emphasis on reproductive potential (fertility rate and natality rate) and recruitment, age at sexual maturity and reproductive senescence, etc;

(ii) factors affecting the survival of juvenile and adult segments of the population, e.g. predation, disease, mother-young relationships and other behavioural phenomena and accidents. In our study of predator-prey relationships particular attention is focussed on the effect of buffer species on the survival of rare or vulnerable prey species, and an attempt to determine and catalogue the conditions when control of the numbers of those predators with few or no natural enemies becomes necessary in a closed ecosystem with man-imposed boundaries. In the case of serious density-independant disease conditions (e.g. anthrax) which can inflict mortality even in populations of low density, such as roan antelope, it is a research objective to develop adequate prophylactic measures, such as aerial innoculation by means of which such populations can be safeguarded;

(iii) sex ratios at birth and amongst adults and the determination of the effects of sex ratio discrepancies on population growth, e.g. the effect of temporary isolation of the sexes on their vulnerability in terms of predation and other mortality factors;

(iv) age structure of the population, which in turn requires the identification of clearly defined age classes and the interpretation of vulnerability and fluctuations in the proportion of different age classes, and

(v) the compilation of life tables and population simulation models particularly as an aid in the determination of population ceilings and the regulation of the numbers of prolific and problem animal species. 
(b) Aspects relating to ecology which include:

(i) local and seasonal movements and concentration areas. A valuable aid in the study of these movements is the capturing and marking of individual animals or the use of radio-telemetric devices. This in turn necessitates a research program to establish the most efficient capture techniques by means of drugs or mechanical means for the individual species;

(ii) food preferences and susceptibility to competition for the food (or water) resource. This again is of vital importance in the case of numerically or physically dominant species such as buffalo, wildebeest, zebra and elephant and the degree of dominance exerted may have an important bearing on the calculation of cropping quotas, particularly in the case of those animals where the regulatory effect of the 'super predator' (primitive man) has been removed from the ecosystem. In the case of rare and endangered species or those with very strict habitat and/or food preferences the competition factor is also of extreme consequence in determining population ceilings. In those national parks with limited area, such as the so-called 'species parks' in the Cape Province, management programs have as their primary objective the provision of optimum conditions for population growth of the Cape mountain zebra and the bontebok, even to the exclusion of all competitive species which may have been associated with these remnant populations during historic times. It is also a declared objective, when numbers permit, to reintroduce both these rare species into at least one alternative conservation area within their former range of distribution - in the same manner as was so admirably achieved with the square-lipped rhinoceros by the Natal Parks, Game and Fish Preservation Board;

(iii) water requirements. The stabilization of natural water supplies, where this is impaired by human demands, particularly outside the borders of parks, and the development and siting of artificial watering points (where this is needed) in our national parks, have as their aim the achieving of optimum utilization of the available plant-food resources. On the other hand, our present policy does consider the need for preserving rare plant and animal species, the maintenance of a seasonal grazing rotation and of strict wilderness areas, and the effect which additional water supplies may have on the population growth of potentially destructive herbivorous or carnivorous populations;

(iv) habitat preferences, sensitivity to habitat changes and availability of suitable habitats (again with emphasis on the rarer and problem species);

(v) range carrying capacity, biomass and energy relationships in the ecosystem. 
litter disposal, encouraging unnatural behaviour in animals (such as begging for food) etc. Even sightseeing, which is normally considered a nonconsumptive use of parks, may alter energy pathways unless it is regulated. Many fragile accessible environments in national parks throughout the world have been so severely damaged by the trampling effect of human feet that recovery may require decades.

These examples of the influence of man on natural ecosystems illustrate something of the conflicts facing park managers. Despite these conflicts, it appears to be feasible to maintain natural relations.

It has long been recognized by the National Parks Board that park ecosystems have a finite capacity for absorbing certain of man's disruptive and consumptive influences, and the number of visitors to our national parks is therefore carefully controlled. In the interest of our primary duty as conservators we consider it a privilege to visit a national park and not a public right, as in so many other parts of the world.

The explanation of natural phenomena to the park visitor is another function of the National Park Service. Interpretation includes exhibits at museums, visitor information centres, and along roadsides, hiking trails and evening programs conducted by Park Service personnel, and self-guiding trails and auto tours. In addition, most of our parks offer a variety of guide books and other publications that explain features of the park.

The gathering and dissemination of the information required for the park's information and interpretative service may be regarded as the most important secondary objective of our research team. An additional research objective in this respect concerns information surveys on our park visitors. Who are they? From where do they come to a given park? Why? What are their expectations? Their disappointments? Their unexpected satisfactions? What is their understanding (or misunderstanding) of the purposes for which parliament established the various parks? And so on.

The research unit also fulfils the following additional functions:

(i) The accumulation, digestion and interpretation of international research findings which are applicable to the preservation and management of the biological resources which fall under the responsibility of the National Parks Board.

(ii) Advising on the biological implications of legislation pertaining to nature conservation, by considering laws, regulations and their enforcement and, in doing so, touching upon public administration.

(iii) Providing extension services, on request, to other disciplines concerned with nature conservation.

(iv) Participation in the in-service training of field staff and the education and public relations work of the organization, ensuring proper biological standards and dissemination of correct information. 
(v) The building up and maintenance of proper reference museums for use by local and visiting research workers. This allows for a certain amount of controlled collecting in all national parks. No indiscriminate collecting, merely to swell the collections of other museums, and such as has been mooted by various individuals, will be condoned, however.

(vi) The writing up of results of research projects as reports for consideration by management, or in the form of scientific articles fit for publication in the Board's own media or in other recognized scientific journals.

A research program can only benefit by actively encouraging universities, private or government research institutes, museums and herbaria, as well as qualified amateur or independant professional investigators or groups to use our national parks for teaching and to participate in research, at the invitation of and under the guidance and supervision of the personnel of the research unit. The Board even offers a number of scholarships and grants for post-graduate or diploma students to conduct research or participate in management programs in all our conserved areas. Encouragement and financial aid is also given to the research staff who wish to read for higher degrees or to attend refresher courses, symposia or workshops in their chosen fields of interest or research.

Man's destruction of wildlife and its environment through the juggernaut of his frightening population explosion is gaining momentum. It could be argued that all ecological research is of relevance to conservation, but there is at present, and in the immediate future, a pressing need not only to create new national parks, but to pay special attention to the main biotic factor (i.e. human influence) above all else. Only through a concerted effort to understand as much as possible of the totality of man's impact on the natural environment, will there be a reasonable chance to arrest or reverse the attrition of our fauna and flora and the habitat, and to look after the remains (de Graaff 1973).

\section{REFERENCES}

BOYD, J M 1972. Scientific investigation in national parks according to an integrated plan. World National Parks. Ed. R van Osten. Brussels: Hayez.

DE GRAAFF, G 1973. Principles and techniques for the management and conservation of fauna and flora in National Parks and game reserves. Address prepared for the International Symposium on 'Planning for Environmental Conservation' Pretoria 4-6 September 1973.

HOUSTON, D B 1971. Ecosystems in National Parks. Science 172: 648-651.

LINN, R M 1976. Introduction to masterplanning. Parks 1(1): 5-8. 